\title{
Occupational Exposure of Pharmacists to Drugs during the Preparation of Powder Drugs in Dispensing Pharmacies
}

\author{
Tsuyoshi Murahashi, ${ }^{*}$ Ayaka Suzuki, Shiho Motojima, and Toshiyuki Higuchi \\ Nihon Pharmaceutical University; 10281 Komuro, Ina-machi, Kita-adachi-gun, Saitama 362-0806, Japan.
}

(Received April 5, 2021; Accepted June 12, 2021)

\begin{abstract}
Occupational exposure of pharmacists to drugs during powder drug preparation in dispensing pharmacies was investigated. First, we determined frequently prescribed tipepidine hibenzate and ambroxol hydrochloride suspended in the air of the dispensing room. The median concentration of the drugs in the air was $0.01 \mu \mathrm{g} / \mathrm{m}^{3}$ and $0.02 \mu \mathrm{g} / \mathrm{m}^{3}, \mathrm{respec}-$ tively; these values indicate that the air in the dispensing room was contaminated with powder drug. To estimate drug exposure during powder drug preparation, drug dust was collected near the nose of workers. Analysis of the active ingredients of the drugs used in the preparation revealed that eight drugs, including bethanechol, L-carbocisteine, and zonisamide, were detected in the range of $1.5-1220 \mu \mathrm{g} / \mathrm{m}^{3}$. Assuming that the respiratory volume of an adult was 0.008 $\mathrm{m}^{3} / \mathrm{min}$, it was estimated that $0.4-36 \mu \mathrm{g}$ of the ingredients were exposed per prescription by multiplying concentration, respiratory volume and sampling time (3-5 min). Furthermore, the effect of wearing a medical mask on the drug powder exposure was evaluated using a self-made apparatus. When the amount of drug powder collected on filters that is either covered with or without a medical mask was compared, the covered filter exhibited reduced drug powder accumulation to less than $10 \%$ the amount collected on the uncovered filter. The present data suggested that a medical mask might decrease the drug dust allergies in dispensing pharmacists.
\end{abstract}

Key words_ occupational exposure; powder drug preparation; dispensing pharmacy; pharmacist

\section{INTRODUCTION}

According to statistics collected in 2018, there are 59613 dispensing pharmacies ("pharmacies" hereafter), 110477 hospitals/clinics, and 240371 pharmacists engaged in medical institutions in Japan. ${ }^{1-3)}$ Since pharmacists routinely prepare powder drugs and crush tablets, drug dust is often spread throughout the dispensing room. This drug dust exposure likely causes health disorders and allergies in pharmacists. The current countermeasures are not yet sufficient. Article 1 of the Pharmacists Act stipulates that one of the duties of a pharmacists is to contribute to public health. ${ }^{4}$ Information and education on work environment management for occupations, such as dye manufacturing, the rubber industry, and nickel smelting are generally sufficient, but the medical profession, including pharmacists, remain behind in this regard. ${ }^{5,6}$

Studies on health disorders in pharmacists caused by drug exposure began in the 1970s, when it was reported that a hospital pharmacist presented an occupational allergy to pancreatin with symptoms, such as runny nose, sneezing and dyspnea. ${ }^{7)}$ A study by

\footnotetext{
*e-mail: tmu@ nichiyaku.ac.jp
}

Fueki ${ }^{8)}$ revealed that many pharmacists had symptoms, such as nasal allergy, pharyngeal discomfort, asthma, atopic dermatitis and contact dermatitis, which are thought to be caused by substances used in the pharmacy, such as diastase and gentian. Furthermore, several reports that problems related to drug exposure due to powder dispensing, tablet crushing, and anticancer drug preparation continue to this day. ${ }^{9-12)}$ These symptoms are collectively called "drug dust allergy" or "pharmaceutical allergy", and include allergic rhinitis, pharyngitis, asthma, allergic conjunctivitis, atopic dermatitis, and contact dermatitis. ${ }^{13)}$ Therefore, it is crucial to prevent occupational exposure to promote safety and pharmaceutical hygiene.

Recently, Inaba et al. ${ }^{10)}$ measured suspended dust and drug ingredient concentration in the air of hospital dispensaries to assess the current status of the work environment for hospital pharmacists. Their study suggests that drug dust control systems should be installed to reduce the concentration of suspended dust in air of the dispensary, because the concentration of drugs in rooms with dust removers was lower than those without. In general, the volumes of dispensing rooms in pharmacies were smaller than those in hospitals, and the drug dust control systems in 
these rooms were insufficient. Therefore, the drug dust issue is more acute in pharmacies, and yet very little research exists for the assessment of suspended dust and drug concentration in the air.

The present study evaluates the degree of drug exposure to pharmacists in dispensing rooms of pharmacies during powder drug preparation using several common powder drugs. To estimate drug exposure during powder drug preparation in pharmacies, suspended dust was collected from the dispensing rooms, and the drug ingredients contained therein were analyzed. The capture efficiency of medical masks for drug dust and drug particle disintegration from using a mortar and pestle and their floating property were also investigated.

\section{MATERIALS AND METHODS}

Chemicals Tipepidine hibenzate, ambroxol hydrochloride, carbamazepine, sodium valproate, Lcarbocisteine, and phenobarbital were purchased from FUJIFILM Holdings Corporation (Tokyo) and bromhexine hydrochloride, bethanechol chloride, zonisamide, and levetiracetam were purchased from Tokyo Chemical Industry Co., Ltd. (Tokyo). For preparation of mobile phase for HPLC studies, HPLC-grade acetonitrile, ammonium acetate, potassium dihydrogen phosphate, trifluoroacetic acid, sodium 1-pentanesulfonate, and phosphoric acid were purchased from FUJIFILM, and water was purified by an Elix-3 (Millipore-Merck KGaA, Darmstadt) .

Analysis of Drug Concentration in the Dispensing Rooms of Pharmacies From 2011 to 2016, suspended dust was collected from the dispensing rooms of four pharmacies in Nagano, Saitama Prefectures and Metropolitan Tokyo, Japan. An air sampler (MP- $\sum 500$ N, SIBATA Scientific Technology Ltd., Saitama) coupled with an open-face filter holder was placed at a position $0.5-2 \mathrm{~m}$ from the dispensing balance on the table. A glass fiber filter (AP2002500, pore size $2.0 \mu \mathrm{m}$, diameter $25 \mathrm{~mm}$, Millipore), prewashed with methanol, was set in the filter holder, and suspended dust was collected at a suction flow rate of $3 \mathrm{~L} / \mathrm{min}$ for $8-9 \mathrm{~h}$. Then, tipepidine hibenzate and ambroxol hydrochloride collected on the filters were analyzed.

Simulation of Drug Exposure to Pharmacists during Powder Drug Preparation In February 2019, four students prepared powder drugs and packed them mechanically at the simulated pharmacy in Ni- hon Pharmaceutical University. They mixed $3.6 \mathrm{~g}$ of Asverin ${ }^{\circledR}$ powder $10 \%$ ( $110.7 \mathrm{mg} / \mathrm{g}$ tipepidine hibenzate, $100 \mathrm{mg} / \mathrm{g}$ tipepidine citrate equivalent, Nipro Pharma Corporation, Osaka) and $2.4 \mathrm{~g}$ of Bisorvon ${ }^{\circledR}$ fine granules $2 \%(20 \mathrm{mg} / \mathrm{g}$ bromhexine hydrochloride, Sanofi S.A., Paris) using a mortar and pestle and packaged them into 12 packages with an automatic dividing and packaging machine (SL21S, Takazono Corporation, Tokyo). This operation was repeated three times within $10 \mathrm{~min}$. The filter holder was clipped to the collar of the lab coat, and the air sampler was carried to collect the suspended dust, then tipepidine hibenzate and bromhexine hydrochloride on the filters were analyzed. The study was approved by the ethical board of Nihon Pharmaceutical University (Approval No. NPE3-2).

Measurement of Drug Exposure to Pharmacists by Powder Drug Preparation in Pharmacies From March to August 2019, scattered drug dust was collected at two pharmacies in Metropolitan Tokyo and Saitama Prefecture during powder drug preparation. The filter holder was clipped to the collar of the lab coat, and the air sampler collected suspended dust for 3-5 min during the preparation of each prescription. The drug ingredients on the filters were analyzed. The study was approved by the ethical board of Nihon Pharmaceutical University (Approval No. NPE3-2).

Examination of Protective Effect of Medical Mask on Drug Exposure The protective effect of medical masks on drug exposure was investigated using the apparatus shown in Fig. 1. A desktop fan (YDSCA184, Yamazen Corporation, Osaka) was attached to one side of a VU polyvinyl chloride pipe for drainage $(200 \mathrm{~mm}$ o.d. $\times 2000 \mathrm{~mm}$, Shin-Etsu Polymer Co., Ltd., Tokyo), and the wind speed switch was set to $3.2 \mathrm{~m} / \mathrm{s}$ as measured using an anemometer (ISA-700, SIBATA). A hole of $10 \mathrm{~mm}$ was made in the upper part $300 \mathrm{~mm}$ from the fan side, a plastic funnel was inserted, and the mixture of $10.8 \mathrm{~g}$ of Asverin $^{\circledR}$ powder $10 \%$ and $7.2 \mathrm{~g}$ of Bisorvon ${ }^{\circledR}$ fine granules $2 \%$ was added very slowly over $3 \mathrm{~min}$. Other holes of $10 \mathrm{~mm}$ were made on the left and right side at a position of $1500 \mathrm{~mm}$ from the funnel, a silicon tube ( $10 \mathrm{~mm}$ o.d., $\quad 7 \mathrm{~mm}$ i.d. $\times 500 \mathrm{~mm}) \quad$ was passed through each hole, two open-face filter holders were connected to the inside, and two air samplers were connected to the outside. One of the filter holders was covered with a medical mask (polypropylene nonwoven fabric 3-layer structure, BMC, Tokyo) and fix- 


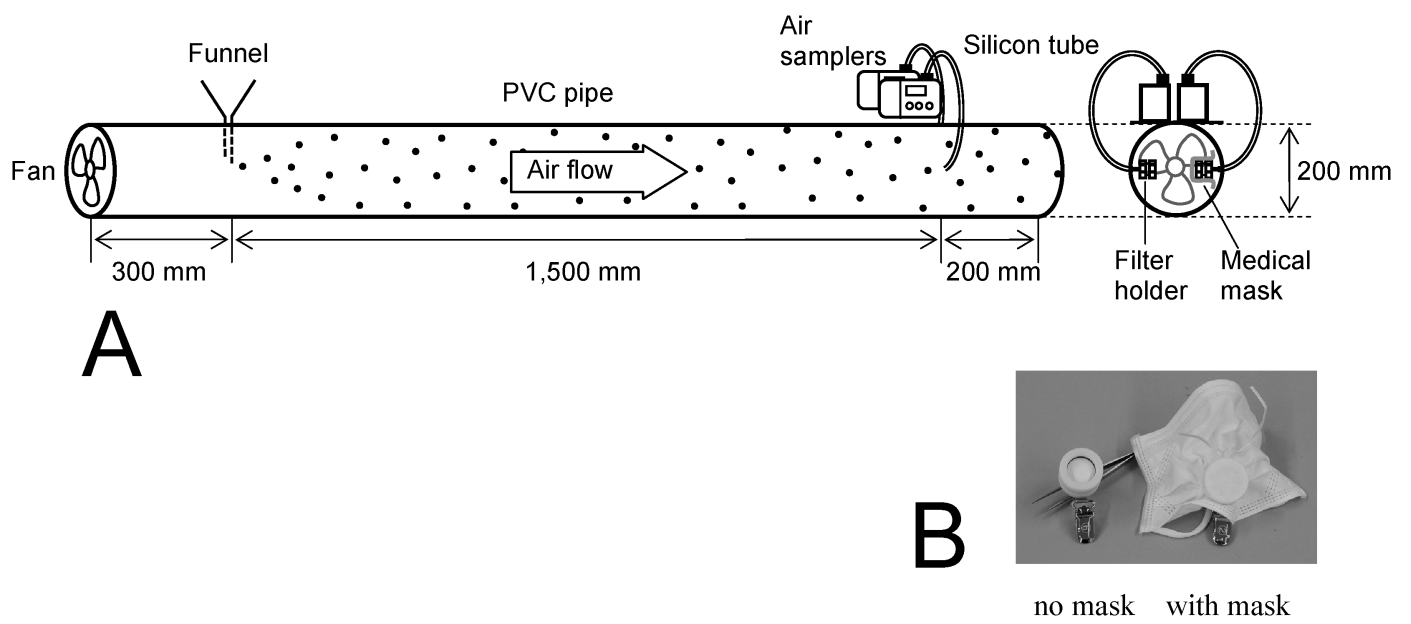

Fig. 1. An Apparatus for Assessing the Reduction in Drug Exposure by Wearing a Medical Mask A: An apparatus for assessing the reduction in drug exposure by wearing a medical mask. B: Filter with and without mask.

ed with a wire so that there were no gaps, and drug particulate passing through the medical mask was collected. The other filter holder collected drug particulate without a medical mask. Then, tipepidine hibenzate and bromhexine hydrochloride on the filters were analyzed.

Analysis of Drug Ingredients The filter was placed in a $10 \mathrm{~mL}$ glass beaker with the collection side facing up, $1 \mathrm{~mL}$ of the HPLC mobile phase was added, and ultrasonic waves were applied for 5 min using an ultrasonic cleaner (Branson 3510, Yamato Scientific Co., Ltd., Tokyo). Twenty microliters of the extract were injected into an HPLC system.

The HPLC system consisted of a degasser (DGU20A3, Shimadzu Corporation, Kyoto), a pump (LC20AD), a column oven (CTO-20A), an ultraviolet absorption detector (SPD-20A), an integrator (CR8A), and a sample injector (7725i, Rheodyne, Cotati). Separation columns were Cosmosil 5NPE (nitrophenyl ethyl group-bonded silica gel-filled column, $4.6 \mathrm{~mm}$ i.d. $\times 250 \mathrm{~mm}$, Nacalai Tesque Inc., Kyoto) for analysis of tipepidine hibenzate, ambroxol hydrochloride, and bromhexine hydrochloride, and Inertsil ODS-3 (octadecyl group-bonded silica gel-filled column, $4.6 \mathrm{~mm}$ i.d. $\times 250 \mathrm{~mm}$, GL Science Inc., Tokyo) for analysis of other drugs. The temperature of the column oven was set to $40^{\circ} \mathrm{C}$. Mobile phases were acetonitrile $/ 25 \mathrm{mmol} \mathrm{L}^{-1}$ ammonium acetate solution $(13: 7, \mathrm{v} / \mathrm{v})$ for tipepidine hibenzate, ambroxol hydrochloride and bromhexine hydrochloride, acetonitrile/ $50 \mathrm{mmol} \mathrm{L}^{-1} \mathrm{KH}_{2} \mathrm{PO}_{4}$ solution $(1: 1, \mathrm{v} / \mathrm{v})$ for carbamazepine, zonisamide, sodium valproate, phenobarbital, $0.1 \%$ trifluoroacet- ic acid solution for L-carbocisteine, acetonitrile/ $20 \mathrm{mmol} \mathrm{L}^{-1} \quad \mathrm{KH}_{2} \mathrm{PO}_{4}$ solution $(1: 9, \mathrm{v} / \mathrm{v})$ for levetiracetam, and $0.26 \%$ 1-pentanesulfonate sodium solution/acetonitrile/phosphoric acid $(980: 20: 1$, $\mathrm{v} / \mathrm{v} / \mathrm{v}$ ) for bethanechol. The mobile phase was delivered at a flow rate of $1 \mathrm{~mL} / \mathrm{min}$. The analytes eluted from the separation column were detected by ultraviolet absorption at $254 \mathrm{~nm}$ for tipepidine hibenzate, ambroxol hydrochloride and bromhexine hydrochloride, $240 \mathrm{~nm}$ for sodium valproate, L-carbocisteine and phenobarbital, $210 \mathrm{~nm}$ for carbamazepine and zonisamide and $205 \mathrm{~nm}$ for levetiracetam.

Assessment of Powder Drug Particle Size Distribution after Mixing with a Mortar and Pestle The particle size distribution of $10 \%$ Asverin ${ }^{\circledR}$ powder was measured as follows. Approximately $1 \mathrm{~g}$ of sample was fractionated by particle size with ten Sanpo stainless sieves (diameter $75 \mathrm{~mm}$, opening 20, 40, 53, 75, $106,150,212,300,425$ and $600 \mu \mathrm{m}$, AS ONE Corporation, Osaka). The weight of each sieve with or without sample was measured using an electronic balance (AUW120D, Shimadzu). The particle size distribution of Asverin ${ }^{\circledR}$ powder after the mixing operation was determined by weighing about $1 \mathrm{~g}$ of the sample, lightly stirring with a porcelain mortar and pestle for $1 \mathrm{~min}$, and then the particle size distribution was measured in the same manner. Statistical analyses were performed using the 2013 version of Excel (Microsoft, Redmond). The significance of the differences was determined using the Student $t$-test. A $p$-value $<0.01$ was considered statistically significant.

Approximately $0.3 \mathrm{~g}$ of powder for each particle size $(75-106 \mu \mathrm{m}, 150-212 \mu \mathrm{m}$ and $300-425 \mu \mathrm{m})$ was 
Table 1. Drug Ingredient Concentrations in the Air of the Dispensary Room during Powder Drug Preparation

\begin{tabular}{|c|c|c|c|c|}
\hline $\begin{array}{c}\text { Pharmacy } \\
\text { Date }(\mathrm{y} / \mathrm{m} / \mathrm{d})\end{array}$ & $\begin{array}{l}\text { Sampling } \\
\text { time (h) }\end{array}$ & Ingredients & $\begin{array}{l}\text { Concentration } \\
\left(\mu \mathrm{g} / \mathrm{m}^{3}\right)\end{array}$ & $\underset{(\mu \mathrm{g} / \mathrm{d})}{\text { Exposure }}$ \\
\hline A, Nagano & 9 & Tipepidine hibenzate & 0.23 & 0.99 \\
\hline \multicolumn{5}{|l|}{$2011 / 5 / 17$} \\
\hline B, Saitama & 8 & Ambroxol hydrochloride & $<0.01$ & - \\
\hline \multicolumn{5}{|l|}{$2015 / 5 / 1$} \\
\hline C, Saitama & 8 & Tipepidine hibenzate & $<0.01$ & - \\
\hline $2016 / 3 / 11$ & & Ambroxol hydrochloride & 0.05 & 0.19 \\
\hline C, Saitama & 8 & Tipepidine hibenzate & 0.05 & 0.19 \\
\hline $2016 / 3 / 12$ & & Ambroxol hydrochloride & 0.02 & 0.077 \\
\hline C, Saitama & 8 & Tipepidine hibenzate & $<0.01$ & - \\
\hline $2016 / 3 / 13$ & & Ambroxol hydrochloride & 0.02 & 0.077 \\
\hline D, Tokyo & 8 & Tipepidine hibenzate & 0.02 & 0.077 \\
\hline $2016 / 7 / 20$ & & Ambroxol hydrochloride & 0.21 & 0.81 \\
\hline D, Tokyo & 8 & Tipepidine hibenzate & 0.01 & 0.038 \\
\hline $2016 / 7 / 21$ & & Ambroxol hydrochloride & $<0.01$ & - \\
\hline D, Tokyo & 8 & Tipepidine hibenzate & 0.01 & 0.038 \\
\hline $2016 / 7 / 22$ & & Ambroxol hydrochloride & 0.01 & 0.038 \\
\hline
\end{tabular}

dropped from the top against the background of black plastic cardboard, and continuous shooting was performed using a camera (D7000, Nikon Corporation, Tokyo) equipped with an AF-S DX NIKKOR 35 $\mathrm{mm}$ f/1.8G (ISO1600, shutter speed 1/125 second, aperture F8) from a point $1 \mathrm{~m}$ away. The photo was trimmed and adjusted the brightness and contrast.

\section{RESULTS AND DISCUSSION}

\section{Drug Concentration in the Air of the Dispensing} Rooms in Pharmacies According to the data in the second NDB Open Data, ${ }^{14)}$ tipepidine hibenzate and ambroxol hydrochloride were most frequently prescribed as powder drugs. Therefore, their concentrations in the air of the dispensing rooms were measured by setting the air sampler near the dispensing table (Table 1). Tipepidine hibenzate and ambroxol hydrochloride were detected below $0.23 \mu \mathrm{g} / \mathrm{m}^{3}$ and below $0.21 \mu \mathrm{g} / \mathrm{m}^{3}$, respectively. Medians were $0.01 \mu \mathrm{g} /$ $\mathrm{m}^{3}$ for tipepidine hibenzate and $0.02 \mu \mathrm{g} / \mathrm{m}^{3}$ for ambroxol hydrochloride. Drug exposure $(\mu \mathrm{g} / \mathrm{d})$ was estimated by multiplying drug concentration $\left(\mu \mathrm{g} / \mathrm{m}^{3}\right)$, adult ventilation $\left(0.008 \mathrm{~m}^{3} / \mathrm{min}\right)$ and exposure time (min). The total drug ingredient (tipepidine hibenzate and ambroxol hydrochloride) exposure was the sum of each exposure. The calculated exposure value was below $0.99 \mu \mathrm{g} / \mathrm{d}$ with a median of $0.17 \mu \mathrm{g} / \mathrm{d}$. As the sum of adult daily dose of tipepidine hibenzate and ambroxol hydrochloride is $177.9 \mathrm{mg}$, the total drug exposure value was about $1 / 1000000$ of the daily dose, suggesting that there is no problem if it is taken orally. However, exposing these drugs can cause allergic reactions to the nose, throat, eyes, and skin, so even a small weight of exposed drugs may develop depending on the constitution of the pharmacist.

Estimation of Drug Exposure during Powder Drug Preparation in Pharmacies A simulation experiment was performed to estimate drug exposure during powder drug preparation in the simulation pharmacy of our university. To evaluate exposure of drug more accuracy, drug dust was collected from near the nose. The atmospheric concentration of tipepidine hibenzate ranged $65-320 \mu \mathrm{g} / \mathrm{m}^{3}$, which was much higher than that (below $0.23 \mu \mathrm{g} / \mathrm{m}^{3}$ ) measured at near the dispensing table (Table 2). The total drug exposure $(\mu \mathrm{g} /$ prescription) was estimated by multiplying total drug concentration $\left(\mu \mathrm{g} / \mathrm{m}^{3}\right)$, adult ventilation $(0.008$ $\mathrm{m}^{3} / \mathrm{min}$ ) and preparation time (5 $\mathrm{min} /$ prescription) . Calculated total drug exposure was in the range of 2.0 $-10.7 \mu \mathrm{g} /$ prescription with a median of $2.5 \mu \mathrm{g} /$ prescription (Table 2). Total drug exposures of student $\mathrm{C}$ were much higher than those of the others, although four operators prepared drugs using the same procedure. This difference may be attributed to 
Table 2. Drug Concentrations in the Air during Simulated Powder Drug Preparation

\begin{tabular}{|c|c|c|c|}
\hline Student & Ingredients & $\begin{array}{l}\text { Concentration } \\
\left(\mu \mathrm{g} / \mathrm{m}^{3}\right)\end{array}$ & $\begin{array}{c}\text { Exposure } \\
(\mu \mathrm{g} / \text { prescription })\end{array}$ \\
\hline \multirow[t]{2}{*}{ A } & Tipepidine hibenzate & 75 & 2.0 \\
\hline & Bromhexine hydrochloride & 13 & 0.35 \\
\hline \multirow[t]{2}{*}{ B } & Tipepidine hibenzate & 90 & 2.4 \\
\hline & Bromhexine hydrochloride & 8.2 & 0.22 \\
\hline \multirow[t]{2}{*}{$\mathrm{C}$} & Tipepidine hibenzate & 320 & 8.5 \\
\hline & Bromhexine hydrochloride & 82 & 2.2 \\
\hline \multirow[t]{2}{*}{$\mathrm{D}$} & Tipepidine hibenzate & 65 & 1.7 \\
\hline & Bromhexine hydrochloride & 11 & 0.3 \\
\hline
\end{tabular}

Table 3. Drug Exposure during Powder Drug Preparation

\begin{tabular}{llcc}
\hline \hline $\begin{array}{l}\text { Sampling site } \\
\text { Date }(\mathrm{y} / \mathrm{m} / \mathrm{d})\end{array}$ & \multicolumn{1}{c}{ Ingredients } & $\begin{array}{c}\text { Concentration } \\
\left(\mu \mathrm{g} / \mathrm{m}^{3}\right)\end{array}$ & $\begin{array}{c}\text { Exposure } \\
(\mu \mathrm{g} / \text { prescription })\end{array}$ \\
\hline $\begin{array}{l}\text { Tokyo } \\
(2019 / 3 / 12)\end{array}$ & Bethanechol & 1220 & 36 \\
\hline Tokyo & Carbamazepine & 12 & 0.48 \\
$(2019 / 4 / 10)$ & Sodium valproate & 11 & 0.44 \\
& Ambroxol hydrochloride & 1.5 & 0.06 \\
\hline Tokyo & L-Carbocisteine & 130 & 5.2 \\
$(2019 / 4 / 19)$ & & & 6.3 \\
\hline Saitama & Zonisamide & 157 & 3.5 \\
$(2019 / 7 / 2)$ & Carbamazepine & 87 & 0.84 \\
\hline Saitama & Sodium valproate & 21 & 1.7 \\
$(2019 / 7 / 10)$ & Phenobarbital & 42 & 0.40 \\
\hline Saitama & Levetiracetam & 10 & \\
$(2019 / 8 / 6)$ & & & \\
\hline
\end{tabular}

not only the dispensed weight of powdered drugs but also to individual differences in the handling.

Next, we collected drug dust during powder drug preparation according to prescriptions at pharmacies in Metropolitan Tokyo and Saitama Prefecture. Bethanechol, carbamazepine, sodium valproate, ambroxol hydrochloride, L-carbocisteine, zonisamide, phenobarbital and levetiracetam were detected in the range of $1.5-1220 \mu \mathrm{g} / \mathrm{m}^{3}$ (Table 3). Because the lowest concentration $\left(1.5 \mu \mathrm{g} / \mathrm{m}^{3}\right)$ was about 6.5 times higher than that in the air near the dispensing table $\left(0.23 \mu \mathrm{g} / \mathrm{m}^{3}\right)$ in Table 1 , there may be small positive error. The total drug exposure was in the range of $0.4-36 \mu \mathrm{g} /$ prescription. Compared to the simulation experiment, the range of the exposure was wide because situations such as prescription, operator, and environment are various, but the median
$(3.9 \mu \mathrm{g} /$ prescription) was similar to that in the simulation experiment $(2.5 \mu \mathrm{g} /$ prescription $)$. Judging from these results, drug exposure in pharmacists handling powder drug is higher than in those that do not. Although the exposure to the ingredient was lower than $1 / 1000$ of the daily dose, allergic symptoms can develop. Countermeasures to reduce drug exposure will be necessary.

Effect of Reducing Drug Exposure by Wearing a Medical Mask To reduce drug exposure, installing dust removers and granulating powders have been common strategies. ${ }^{15-17)}$ In this study, we investigated the effect of wearing a medical mask on reducing drug exposure. An apparatus shown in Fig. 1 was assembled, suspended Asverin ${ }^{\circledR}$ powder and Bisorvon ${ }^{\circledR}$ fine granules were collected on filters with or without a medical mask, and tipepidine hibenzate and brom- 
Table 4. Effect of Medical Masks on Drug Exposure

\begin{tabular}{|c|c|c|c|}
\hline \multirow{2}{*}{ Drug ingredient } & \multicolumn{2}{|c|}{ Weight of drug ( $\mu \mathrm{g} /$ filter $)$} & \multirow{2}{*}{$\underset{(\%)}{\text { Removal rate }}$} \\
\hline & without mask & with mask & \\
\hline \multicolumn{4}{|l|}{ run 1} \\
\hline Tipepidine hibenzate & 1.48 & 0.003 & \multirow{2}{*}{99.7} \\
\hline Bromhexine hydrochloride & 0.357 & 0.002 & \\
\hline \multicolumn{4}{|l|}{ run 2} \\
\hline Tipepidine hibenzate & 1.20 & 0.115 & \multirow{2}{*}{91.1} \\
\hline Bromhexine hydrochloride & 0.329 & 0.021 & \\
\hline \multicolumn{4}{|l|}{ run 3} \\
\hline Tipepidine hibenzate & 2.40 & 0.208 & \multirow{2}{*}{91.4} \\
\hline Bromhexine hydrochloride & 0.604 & 0.049 & \\
\hline \multicolumn{4}{|l|}{ Mean \pm S.D. } \\
\hline Tipepidine hibenzate & $1.69 \pm 0.63$ & $0.11 \pm 0.10$ & \multirow{2}{*}{$94.1 \pm 0.49$} \\
\hline Bromhexine hydrochloride & $0.43 \pm 0.15$ & $0.02 \pm 0.02$ & \\
\hline
\end{tabular}

hexine hydrochloride on the filters were analyzed ( $\mathrm{Ta}$ ble 4). When the filter was not covered with a mask, the total concentration of tipepidine hibenzate and bromhexine hydrochloride in the air was detected in the range of 1.53-3.00 $\mu \mathrm{g} /$ filter. In contrast, when the filter was covered with a medical mask it reduced the range to $0.005-0.257 \mu \mathrm{g} /$ filter. Removal rate (\%) was calculated by percentage of drug weight on the filter without mask to the difference between drug weight without the mask to with the mask. The removal rates are listed in Table 4. Thus, wearing a medical mask removed more than $90 \%$ of the drug on the filter. These results suggested that the wearing a medical mask was effective in reducing the risk of drug exposure.

\section{Drug Particle Disintegration by Mixing with a Mor-} tar and Pestle Powder drug preparation consists of the following four steps: (1) weighing each powder, (2) mixing the powders, (3) transferring them to a dividing and packaging machine, and (4) cleaning. Drug particles may disintegrate on mixing using a mortar and pestle. In generally, coarser particles settle faster, and conversely, finer particles float in the air for long time. Therefore, we compared the particle size distribution of Asverin ${ }^{\circledR}$ powder before and after the mixing with a mortar and pestle. As shown in Fig. 2 , the percentage of original powder was significantly higher than that of powder after mixing in each class of large particles $(212-425 \mu \mathrm{m})$, while the opposite result was obtained for small particles $(20-150 \mu \mathrm{m})$. Thus, mixing using a mortar and pestle caused particle disintegration.
Then, the sedimentation property of the sifted particles was investigated. Particles of diameter 300-425 $\mu \mathrm{m}, 150-212 \mu \mathrm{m}$, and $75-106 \mu \mathrm{m}$ were freely dropped and images were captured at intervals of $1 / 6$ th of a second (Fig. 3). In the case of 300-425 $\mu \mathrm{m}$ particles, all of the particulates fell within $1 / 2$ second. Finer particles of diameter $150-212 \mu \mathrm{m}$ fell in a streamlined manner, within 1 second, without drifting. On the other hand, the finest particles of 75-106 $\mu \mathrm{m}$ took more than 2 seconds to fall giving a smoke-like appearance and some of them remained floating in the air. These results suggested that the mixing using a mortar and pestle increases the drug exposure to pharmacists by floating drug dust during mixing, transfer, and cleaning procedure, not only due to the increased exposure time, but also drug particles disintegration. Scattering in layers without mixing using a mortar and pestle is effective to reduce drug exposure.

Taken together, this study suggests that the drug dust related symptoms are more acute in the relatively small pharmacies compared with those at hospital pharmacies. Inaba et al. ${ }^{18,19)}$ reported that many pharmacists involved in dispensing powders and crushed tablets have allergies or inflammation in their nose, mouth, throat, and eyes. Some pharmacies do not have a dust remover. Installing and properly operating a dust remover reduces dust considerably, but the more immediate preventative measure is to wear a medical mask. Currently, pharmacists have started wearing masks due to the Covid-19 pandemic. However, prior to pandemic, masks were not worn, as they partially hide facial expressions and thus ad- 


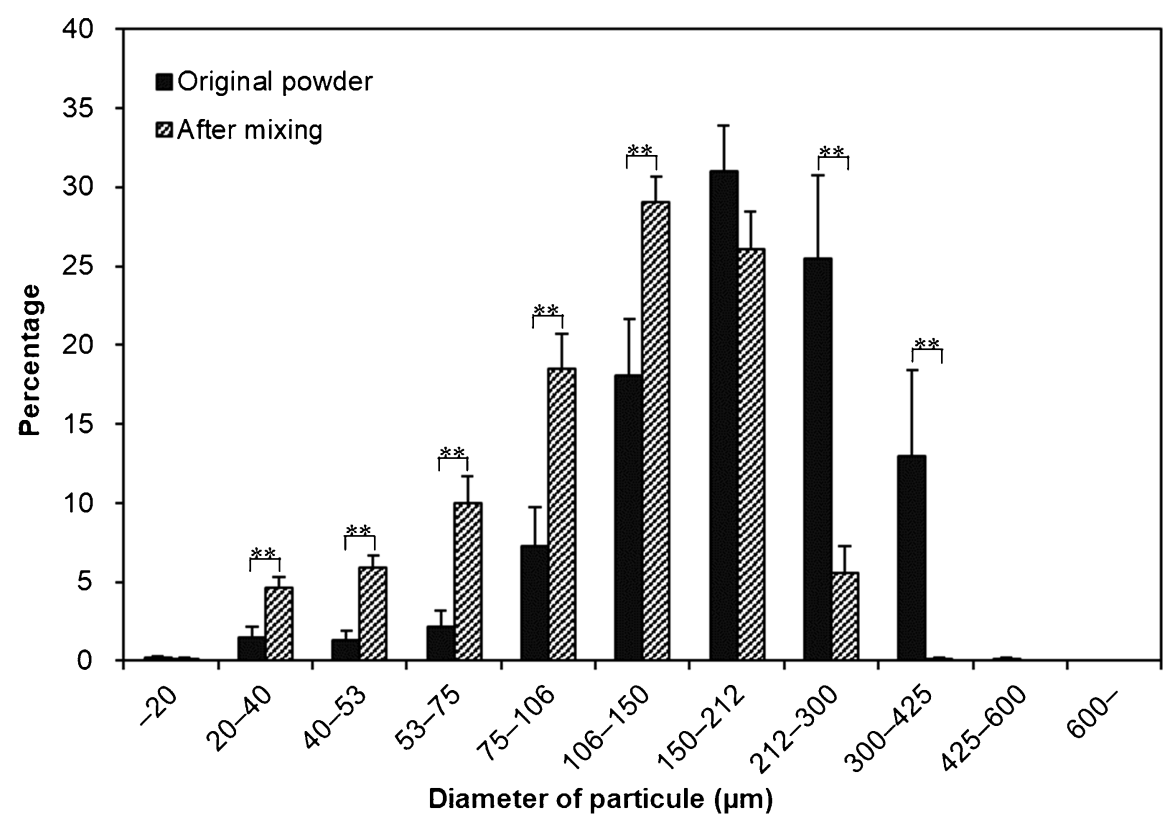

Fig. 2. Changes in Size Distribution of Asverin ${ }^{\circledR}$ Powder by Mixing with a Mortar and Pestle Symbols and bars represent mean and S.D., respectively $(n=5) .{ }^{* *}$, significant $(p<0.01)$.

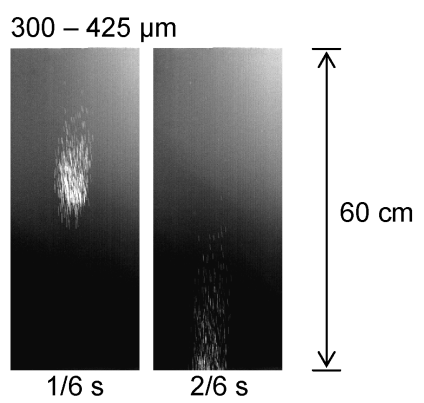

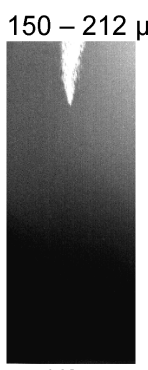

$1 / 6 \mathrm{~s}$
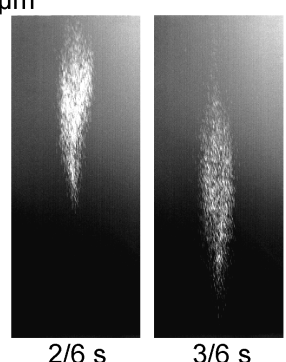

$3 / 6 \mathrm{~s}$
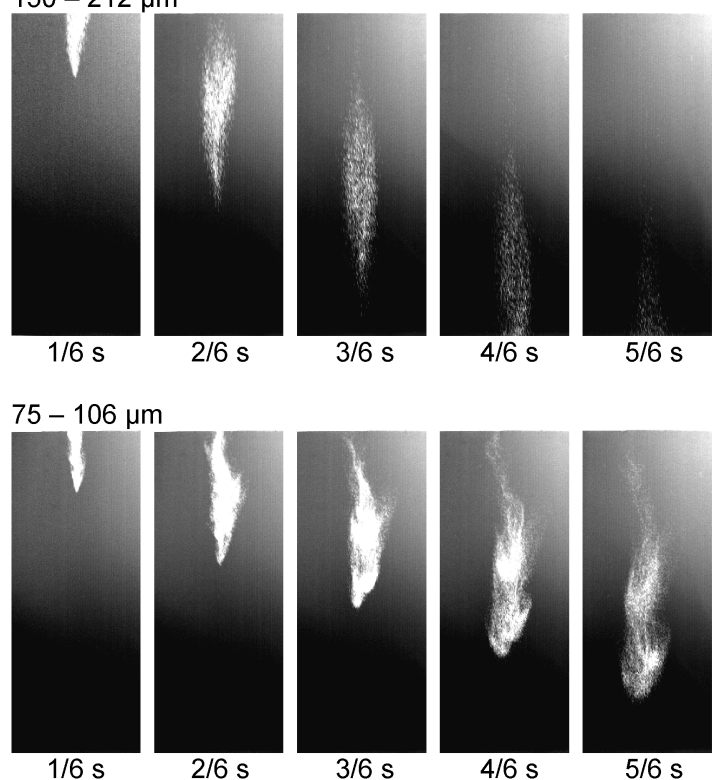

$5 / 6 \mathrm{~s}$
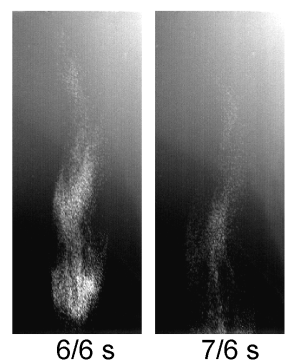

Fig. 3. Duration of Fall of Drug Powder of Different Particle Sizes Photos taken every $1 / 6$ of a second. 
versely affected communication with clients. ${ }^{20,21)}$ More than preventing infection, the presented data suggested that the wearing a medical mask is important for the prevention of occupational drug exposure in dispensing pharmacists, and that awareness and education should be provided for that purpose. Furthermore, guidelines of drug concentrations in the air in closed dispensing rooms are needed to inform the importance of preventing drug exposure during powder preparation. Although the results of this study are relevant in a limited number of pharmacies of certain dimensions, further studies are in progress to at pharmacies of various sizes and facilities.

Acknowledgments We would like to thank the pharmacists and students who collected the samples and participated in the dispensing simulation and drug analysis and faculty members for their helpful advice on this research. We would also like to thank referees for their kindness and helpful advice on this report.

Conflicts of Interest The authors declare no conflict of interest.

\section{REFERENCES}

1) Ministry of Health, Labour and Welfare. 'Number of pharmacies': 〈https://www. mhlw.go.jp / toukei / youran / indexyk_2_4. html $\rangle$, cited 26 July, 2020.

2) Ministry of Health, Labour and Welfare. 'Number of medical institutions': 〈https:// www.mhlw.go.jp/toukei/youran/indexyk_2 2.html $\rangle$, cited 26 July, 2020 .

3) Ministry of Health, Labour and Welfare. 'Pharmacists': 〈https: // www.mhlw.go.jp / toukei/saikin/hw/ishi/18/dl/kekka-3.pdf $\rangle$, cited 26 July, 2020.

4) Ministry of Internal Affairs and Communications, "Pharmacists Act": 〈https://elaws.egov.go.jp/search/elawsSearch/elaws_search/ $\operatorname{lsg} 0500$ / detail?lawId $=335$ AC0000000146 $\rangle$, cited 15 October, 2020.
5) Kiyono M., "Eiseiyakugaku Kiso-Yobo-Rinsho," ed. by Imai H., Ogura Y., Nankodo Co., Ltd., Tokyo, 2020, pp.136-143.

6) Okazaki R., J. UOEH, 36, 27-31 (2014).

7) Nakamura S., Allergy, 20, 361-364 (1971).

8) Fueki R., Farumashia, 7, 364-368 (1971).

9) Yoshida J., Kosaka H., Tomioka K., Kumagai S., J. Occup. Health, 48, 517-522 (2006).

10) Inaba R., Hioki A., Kondo Y., Nakamura H., Nakamura M., Environ. Health Prev. Med., 21, 105-110 (2016) .

11) Maeda S., Takahashi E., Tayama Y., Kitamura S., Tsukamoto T., Miyake K., Sugihara K., Fundam. Toxicol. Sci., 3, 177-183 (2016).

12) Matsuda T., Tanimukai M., Yazawa S., JJOMT, 65, 295-302 (2017).

13) Kataura A., Kawaguchi E., Kimura T., Akiyama T., Jibi Inkoka Tembo, 16, 419-424 (1973).

14) Ministry of Health, Labour and Welfare. '2nd NDB Open Data':〈https://www.mhlw.go.jp/ stf/seisakunitsuite/bunya/0000177221.html $\rangle$, cited 7 August, 2018.

15) Hayashi H., Akita M., Kondo G., Suhara K., Jpn. J. Hosp. Pharm., 6, 220-226 (1980) .

16) Takayama K., Seino T., Sugiura M., Nakamura H., Uchino K., Nakamura K., Sato H., Iga T., Yakugaku Zasshi, 119, 429435 (1999).

17) Aoyama T., Nakao Y., Horioka M., Yamaguchi T., Mizutani K., Jpn. J. Hosp. Pharm., 12, 350-355 (1986).

18) Inaba R., Kondo Y., Hioki A., JJOMT, 60, 23-31 (2012).

19) Inaba R., Hioki A., Kondo Y., Nakamura H., Nakamura M., Ind. Health, 53, 100-108 (2015)

20) Tamura E., Kishimoto K., Fukushima N., Yakugaku Zasshi, 133, 737-745 (2013).

21) Kishimoto K., Hasaka A., Yamaura K., Fukushima N., Yakugaku Zasshi, 136, 14011413 (2016). 